\title{
Skeletal involvement in Gaucher disease: extent of bone disease, splenic volume, and quality of life
}

Envolvimento ósseo na doença de Gaucher: extensão do acometimento ósseo, volume esplênico e qualidade de vida

\section{Ricardo Andrade Fernandes de Mello ${ }^{1, a}$, Melissa Bosi Nonato Mello ${ }^{2, b}$, Laís Bastos Pessanha ${ }^{1, c}$, Ana Paula Alves Fonseca ${ }^{1, d}$}

1. Department of Internal Medicine, Universidade Federal do Espírito Santo (UFES), Vitória, ES, Brazil. 2. Centro Capixaba de Oncologia (Cecon), Vitória, ES, Brazil.

Correspondence: Dr. Ricardo Andrade Fernandes de Mello. Universidade Federal do Espírito Santo - Departamento de Clínica Médica. Avenida Marechal Campos, 1468, Nazareth. Vitória, ES, Brazil, 29047-105. Email: ricardoafmello@gmail.com.

a. https://orcid.org/0000-0002-7723-189x; b. https://orcid.org/0000-0002-6284-1097; c. https://orcid.org/0000-0002-8998-3028;

d. https://orcid.org/0000-0001-7112-7787.

Received 26 January 2020. Accepted after revision 3 April 2020.

How to cite this article:

Mello RAF, Mello MBN, Pessanha LB, Fonseca APA. Skeletal involvement in Gaucher disease: extent of bone disease, splenic volume, and quality of life. Radiol Bras. 2021 Mar/Abr;54(2):71-76.

Abstract Objective: To investigate the correlations among the extent of bone involvement, splenic volume, and quality of life in patients with Gaucher disease.

Materials and Methods: This was a descriptive, prospective cross-sectional study of 18 patients with Gaucher disease who underwent 3-T magnetic resonance imaging of both femurs and the lumbar spine. Semiquantitative analyses were performed on the basis of the bone marrow burden (BMB) score. We looked for linear relationships among the variables splenic volume, quality of life score, and BMB score.

Results: We identified a linear relationship between the BMB scores and splenic volume. The quality of life score showed no statistically significant relationship with splenic volume or the BMB score.

Conclusion: The linear relationship between the BMB score and the splenic volume indicates that the extent of bone disease is greater in individuals with splenomegaly. No correlation was found between the BMB and quality of life scores, illustrating the insidious and silent progression of Gaucher disease.

Keywords: Gaucher disease; Magnetic resonance imaging; Musculoskeletal system; Hematologic diseases.

Resu mo Objetivo: Investigar a correlação entre a extensão do envolvimento ósseo, o volume esplênico e a qualidade de vida em pacientes com doença de Gaucher.

Materiais e Métodos: Estudo descritivo, prospectivo e transversal de 18 pacientes com doença de Gaucher submetidos a ressonância magnética de 3-T de ambos os fêmures e da coluna lombar. Análise semiquantitativa foi feita utilizando o escore bone marrow burden (BMB). Correlação linear foi estudada para as variáveis volume esplênico, qualidade de vida e escore BMB.

Resultados: Uma correlação linear entre os escores BMB e volume esplênico foi demonstrada. Em relação ao índice de qualidade de vida, não foi observada correlação estatisticamente significante nem com o volume esplênico e nem com o escore BMB.

Conclusão: Nosso estudo demonstrou uma correlação linear entre o escore BMB e o volume esplênico, correspondendo a maior extensão de doença óssea em indivíduos com maior esplenomegalia. Nenhuma correlação foi encontrada entre o escore BMB e a qualidade de vida, indicando a natureza insidiosa e a progressão silenciosa da doença de Gaucher.

Unitermos: Doença de Gaucher; Ressonância magnética; Sistema musculoesquelético; Doenças hematológicas.

\section{INTRODUCTION}

Gaucher disease (GD) was the first reported lysosomal storage disease and is the most common type of lipidosis. It is caused by hereditary deficiency of the lysosomal enzyme glucocerebrosidase (or beta-glucosidase), which hydrolyzes glucosylceramide (glucocerebroside) into glucose and ceramide ${ }^{(1,2)}$. The accumulation of glucocerebroside in the bone marrow leads to osteopenia, lytic lesions, pathological fractures, chronic bone pain, bone crises, and infarcts ${ }^{(3,4)}$. The incidence of bone neoplasms has also been shown to be higher in patients with $\mathrm{GD}^{(5,6)}$.
There are different types of GD, and signs and symptoms of the disease vary widely, even within the same type. It can be classified into two main groups: non-neuronopathic GD (type 1) and neuronopathic GD, in which the central nervous system is involved (types 2 and 3). Skeletal involvement is seen on the radiographs of most patients with GD, who are often asymptomatic ${ }^{(7)}$. The severity of bone involvement and the rate of progression vary considerably in GD, although the disease is typically more aggressive in patients who present with symptoms during childhood $^{(8,9)}$. 
The progression of many bone complications can be halted or reversed by enzyme replacement therapy (ERT), although osteonecrosis, osteosclerosis, and vertebral fracture may be irreversible, which can have a significant impact on quality of life ${ }^{(10,11)}$. Therefore, bone disease may be the most debilitating and incapacitating aspect of type $1 \mathrm{GD}$ and should be monitored routinely and early ${ }^{(12-15)}$. The extent of bone marrow infiltration has been shown to be one of the most important parameters for evaluating the severity of GD, and various classifications have been used $^{(16-18)}$. Quantifying bone involvement has therefore become increasingly important in clinical management, not only to determine the eligibility of each patient but also to monitor the effects of therapy, given that ERT is currently costly ${ }^{(19,20)}$.

The broad spectrum of clinical manifestations in GD and its unpredictable progression underscore the need for the use of instruments that facilitate the objective prediction of the prognosis and need for therapy ${ }^{(21,22)}$. Quantitative and semiquantitative scoring systems serve this purpose for a number of diseases, and the bone marrow burden (BMB) score, based on magnetic resonance imaging (MRI), has proven to be a reliable tool for demonstrating a response to ERT in type $1 \mathrm{GD}^{(3,23,24)}$. Because of its high sensitivity in the detection of focal and diffuse pathologies, including bone infarction, avascular necrosis, trauma, infection, and bone marrow infiltration by Gaucher cells, MRI is the method of choice for the evaluation of bone involvement in GD. To evaluate the impact that the disease has on patients, health-related quality of life questionnaires, such as the Medical Outcomes Study 36Item Short Form Health Survey (SF-36), are commonly applied to measures of function in clinical settings, providing self-report information on how patients perceive their functioning in life ${ }^{(23)}$.

The purpose of this study was to investigate the correlations among the extent of bone involvement (BMB score), splenic volume, and quality of life in patients with type $1 \mathrm{GD}$. We also attempted to determine whether selfreported physical, social, and mental functioning correlate with the extent of bone disease, which may have implications for treatment planning.

\section{MATERIALS AND METHODS}

\section{Patients}

This was a prospective, cross-sectional study conducted at a referral center for GD between February and October of 2014. The study population comprised 18 adult patients ( 10 females and 8 males) with a confirmed diagnosis of GD, characterized by decreased acid beta-glucosidase activity in peripheral blood leukocytes and clinical features consistent with type 1 disease. Two of the 18 patients $(11 \%)$ had undergone splenectomy. The study was approved by the local research ethics committee, and all participating patients gave written informed consent.

\section{MRI}

All patients underwent MRI of the lumbar spine and both femurs in a 3-T MRI scanner (Achieva; Philips, Best, The Netherlands). The lumbar spine imaging consisted of sagittal turbo spin-echo (TSE) T1-weighted sequences-repetition time/echo time (TR/TE), 344/11 ms; bandwidth, $308.8 \mathrm{~Hz}$; slice thickness, $4 \mathrm{~mm}$; number of signals averaged, 2 ; matrix, $320 \times 320$; field of view, $27 \mathrm{~cm}^{2}$; and interslice gap, $1 \mathrm{~mm}$-and sagittal TSE T2weighted sequences-TR/TE, 2,927/120 ms; bandwidth, $397.7 \mathrm{~Hz}$; slice thickness, $4 \mathrm{~mm}$; number of signals averaged, 3; matrix, $320 \times 320$; field of view, $27 \mathrm{~cm}^{2}$; and interslice gap, $1 \mathrm{~mm}$. Femoral imaging consisted of coronal TSE T1-weighted sequences-TR/TE, 621/11 ms; bandwidth, $275.6 \mathrm{~Hz}$; slice thickness, $7 \mathrm{~mm}$; number of signals averaged, 2; matrix, $392 \times 157$; field of view, $31 \mathrm{~cm}^{2}$; and interslice gap, $1 \mathrm{~mm}$-and coronal TSE short-tau inversion-recovery sequences-TR/TE, 3,352/120 ms; inversion time, $160 \mathrm{~ms}$; bandwidth, $293.2 \mathrm{~Hz}$; slice thickness, $7 \mathrm{~mm}$; number of signals averaged, 2 ; matrix, $390 \times 313$; field of view, $31 \mathrm{~cm}^{2}$; and interslice gap, $1 \mathrm{~mm}$. In addition, to allow assessment of splenic volume, abdominal images were acquired in an axial TSE T2-weighted sequence-TR/TE, 1,800/90 ms; bandwidth, $320 \mathrm{~Hz}$; slice thickness, $7 \mathrm{~mm}$; number of signals averaged, 2; matrix, $320 \times 320$; field of view, $39 \mathrm{~cm}^{2}$; and interslice gap, $1 \mathrm{~mm}$.

\section{Quality of life}

On the day scheduled for the MRI examination, we applied the SF-36 questionnaire, which consists of a multidimensional evaluation involving 11 items, encompassing eight domains: role-physical; functional capacity; role-emotional; bodily pain; general health; vitality; social functioning; and mental health. The version of the SF-36 employed in this study also includes a question designed to provide a comparative evaluation between the current health status and that of a year ago. Higher SF-36 scores indicate better health-related quality of life.

\section{Splenic volume}

Splenic volume (expressed in cubic centimeters) was measured by tracing the splenic outline. To do so, we selected the appropriate regions of interest manually, respecting the contours of the spleen while excluding large vessels and fissures, from the abdominal T2-weighted TSE images obtained in the axial plane. We used OsiriX opensource software (OsiriX Foundation, Geneva, Switzerland) to trace the outline and calculate the volume.

\section{BMB score}

Semiquantitative analysis were performed using BMB scores, in accordance with previously published criteria ${ }^{(3)}$, based on the evaluation of changes in bone marrow signal intensity and the extent of involvement, in the femurs and in the lumbar spine (Tables 1 and 2, respectively). 
Table 1-F-BMB score, based on MRI signal intensity, together with the sites of femoral involvement.

\begin{tabular}{lcc}
\hline Variable & Signal intensity* & $\begin{array}{c}\text { F-BMB } \\
\text { score }\end{array}$ \\
\hline MRI sequence & & \\
T2-weighted & Hyperintense & 2 \\
T2-weighted & Slightly hyperintense & 1 \\
T2-weighted & Isointense & 0 \\
T2-weighted & Slightly hypointense & 1 \\
T2-weighted & Hypointense & 2 \\
T2-weighted & Mixed type & 3 \\
T1-weighted & Slightly hyperintense or isointense & 0 \\
T1-weighted & Slightly hypointense & 1 \\
T1-weighted & Hypointense & 2 \\
Site of femoral involvement & & \\
Diaphysis & & 1 \\
Proximal epiphysis/apophysis & & 2 \\
Distal epiphysis & & 3 \\
\hline
\end{tabular}

* Determined in relation to the signal intensity of subcutaneous fat.

Source: Adapted with permission from Maas et al. ${ }^{\text {(3). }}$.

Scores for the lumbar spine and for the femurs ranged from 0 to 8 , resulting in a maximum overall BMB score of 16, higher scores being indicative of greater bone marrow involvement. To analyze the separate contributions of the axial and peripheral bone marrow, we subdivided the BMB scores into lumbar spine BMB (L-BMB) and femoral BMB (F-BMB) scores.

\section{Statistical analysis}

Data were analyzed with the IBM SPSS Statistics software package, version 20.0 (IBM Corp., Armonk, NY, USA). We looked for linear relationships among the variables splenic volume, L-BMB score, F-BMB score, BMB score, and quality of life. The Kolmogorov-Smirnov and Shapiro-Wilk normality tests were used in order to deter-
Table 2-L-BMB score, based on MRI signal intensity, together with the patterns of lumbar bone marrow infiltration by Gaucher cells.

\begin{tabular}{lcc}
\hline Variable & Signal intensity* & $\begin{array}{c}\text { L-BMB } \\
\text { score }\end{array}$ \\
\hline MRI sequence & & \\
T2-weighted & Hyperintense & 2 \\
T2-weighted & Slightly hyperintense & 1 \\
T2-weighted & Isointense & 0 \\
T2-weighted & Slightly hypointense & 1 \\
T2-weighted & Hypointense & 2 \\
T1-weighted & Slightly hyperintense & 0 \\
T1-weighted & Isointense & 1 \\
T1-weighted & Slightly hypointense & 2 \\
T1-weighted & Hypointense & 3 \\
Pattern of lumbar infiltration & & \\
Patchy & & 1 \\
Diffuse & & 2 \\
Absence of fat around the basivertebral veins & & 3 \\
\hline
\end{tabular}

* Determined in relation to the signal intensity of healthy intervertebral discs. Source: Adapted with permission from Maas et al. ${ }^{(3)}$.

mine the distribution of the data. Linear regression analysis was used in order to estimate the slope of the relationship that splenic volume has with the L-BMB, F-BMB, $\mathrm{BMB}$, and SF-36 scores. Values of $p<0.05$ were considered statistically significant.

\section{RESULTS}

Demographic characteristics and imaging findings are summarized in Table 3. The study population comprised 18 patients ( 8 men and 10 women), with a mean age of 38.2 years (range, $17-70$ years). Bone complications were seen in 9 patients: 7 had bilateral femoral infarcts; and 3 had femoral head avascular necrosis.

As can be seen in Table 4, the total BMB score ranged from 4 to 14 (mean, 9.83). The L-BMB score ranged from

Table 3-Demographic characteristics and imaging aspects of the patients in the study population $(n=18)$.

\begin{tabular}{|c|c|c|c|c|c|c|c|c|}
\hline ID & Gender & Age (years) & L-BMB score & F-BMB score & BMB score & Splenic volume $\left(\mathrm{cm}^{3}\right)$ & SF-36 score & Bone complications \\
\hline 1 & Male & 70 & 4 & 6 & 10 & 1,616 & 109.4 & Bilateral femoral infarcts \\
\hline 2 & Female & 41 & 6 & 7 & 13 & 456 & 112.4 & Bilateral femoral infarcts \\
\hline 3 & Female & 31 & 5 & 4 & 9 & 448 & 114.4 & - \\
\hline 4 & Male & 17 & 3 & 3 & 6 & 317 & 120 & - \\
\hline 5 & Female & 20 & 5 & 4 & 9 & 347 & 127.8 & Femoral head avascular necrosis \\
\hline 6 & Male & 30 & 6 & 4 & 10 & 1,231 & 120.6 & Femoral head avascular necrosis \\
\hline 7 & Male & 23 & 6 & 4 & 10 & 465 & 122.8 & - \\
\hline 8 & Female & 65 & 3 & 8 & 11 & - & 121.5 & Bilateral femoral infarcts and femoral head avascular necrosis \\
\hline 9 & Male & 40 & 6 & 8 & 14 & - & 118.8 & Bilateral femoral infarcts \\
\hline 10 & Female & 61 & 5 & 6 & 11 & 323 & 105.4 & Bilateral femoral infarcts \\
\hline 11 & Female & 32 & 6 & 6 & 12 & 801 & 93.8 & - \\
\hline 12 & Female & 24 & 7 & 4 & 11 & 1,341 & 112.2 & Bilateral femoral infarcts \\
\hline 13 & Female & 28 & 7 & 6 & 13 & 2,323 & 121 & Bilateral femoral infarcts \\
\hline 14 & Male & 27 & 7 & 6 & 13 & 7,450 & 108.5 & - \\
\hline 15 & Male & 27 & 4 & 2 & 6 & 218 & 114.3 & - \\
\hline 16 & Female & 54 & 4 & 4 & 8 & 118 & 100 & - \\
\hline 17 & Female & 50 & 4 & 0 & 4 & 78 & 120.5 & - \\
\hline 18 & Male & 18 & 5 & 2 & 7 & 386 & 106.5 & - \\
\hline
\end{tabular}


3 to 7 (mean, 5.17), and the F-BMB score ranged from 0 to 8 (mean, 4.67). Splenic volume ranged from $78 \mathrm{~cm}^{3}$ to $7,450 \mathrm{~cm}^{3}$ (mean, $1,119.88 \mathrm{~cm}^{3}$ ). Two patients had undergone splenectomy. The SF-36 (quality of life) score ranged

Table 4-Descriptive statistics for the variables.

\begin{tabular}{lcccccc}
\hline Variable & $\mathrm{N}$ & Mean & Median & $\begin{array}{c}\text { Mini- } \\
\text { mum }\end{array}$ & $\begin{array}{c}\text { Maxi- } \\
\text { mum }\end{array}$ & $\begin{array}{c}\text { Standard } \\
\text { error }\end{array}$ \\
\hline L-BMB score & 18 & 5.17 & 5 & 3 & 7 & 1.29 \\
F-BMB score & 18 & 4.67 & 4 & 0 & 8 & 2.14 \\
Total BMB score & 18 & 9.83 & 10 & 4 & 14 & 2.79 \\
Splenic volume $\left(\mathrm{cm}^{3}\right)$ & 16 & $1,119.88$ & 452 & 78 & 7,450 & $1,799.37$ \\
SF-36 score & 18 & 113.88 & 114.35 & 93.8 & 127.8 & 8.78 \\
\hline
\end{tabular}

from 93.8 to 127.8 (mean, 113.88). Those variables were correlated by means of linear regression models. We found that the splenic volume had linear relationships with the total BMB (Figure 1), L-BMB, and F-BMB scores $(p<$ 0.05 for all), the correlations being of equal strength for the L-BMB and F-BMB scores $\left(r^{2}=0.39\right.$ and $p<0.001$ for both). However, the BMB score was a better alternative in this sense, because it presented a lower confidence interval and standard error, which allows greater accuracy in the correlation with the splenic volume $\left(r^{2}=0.40\right.$ and $p$ $<0.001)$. The SF-36 score did not show a statistically significant relationship with the splenic volume $(p=0.727)$ or the BMB score $(p=0.384)$ (Figure 2).
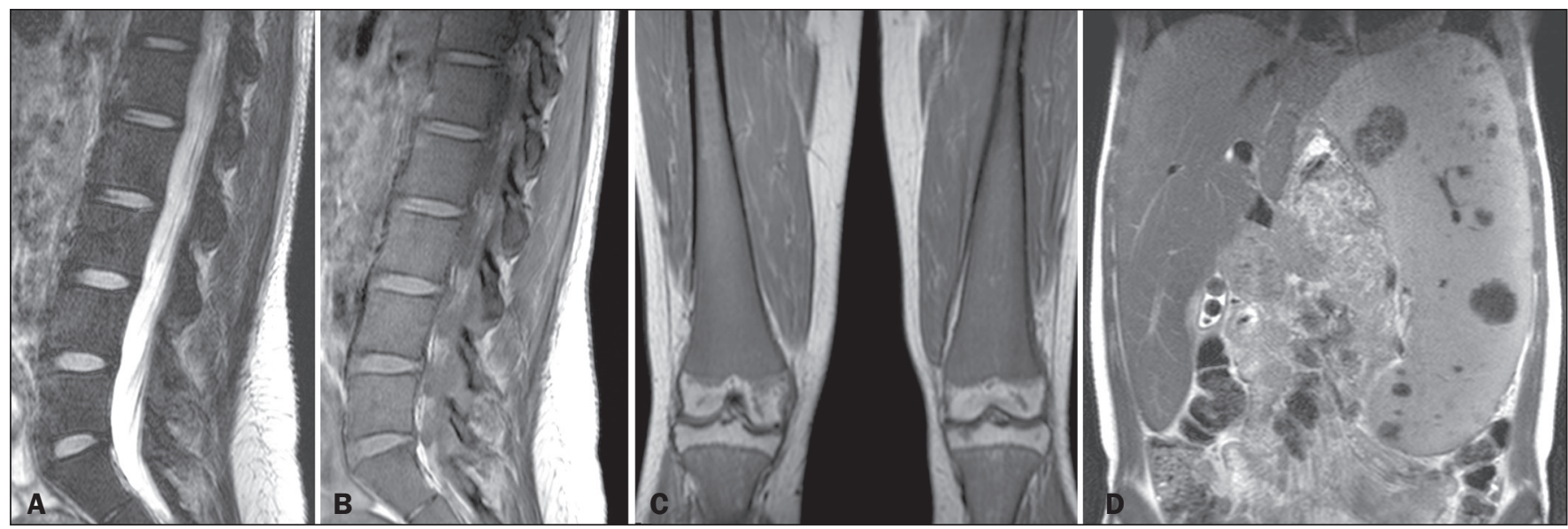

Figure 1. MRI of a 28-year-old woman with GD, showing extensive bone involvement with a high BMB score, together with splenomegaly (splenic volume of 2,323 $\mathrm{cm}^{3}$ ). Sagittal T2-weighted (A) and T1-weighted (B) images of the lumbar spine, showing lower signal intensity in bone marrow than in the disc and presacral fat After suppression of the fat surrounding the basivertebral veins, the signal intensity and extent scores were 4 and 3 , respectively, resulting in an L-BMB score of 7. C: Coronal T1-weighted image of both femurs, which were scored 3 for signal intensity and 3 for the extent of involvement, infiltration of distal epiphyses being detected, resulting in an F-BMB score of 6. D: Coronal T2-weighted image of the abdomen, demonstrating massive splenomegaly, with multiple splenic infarcts.
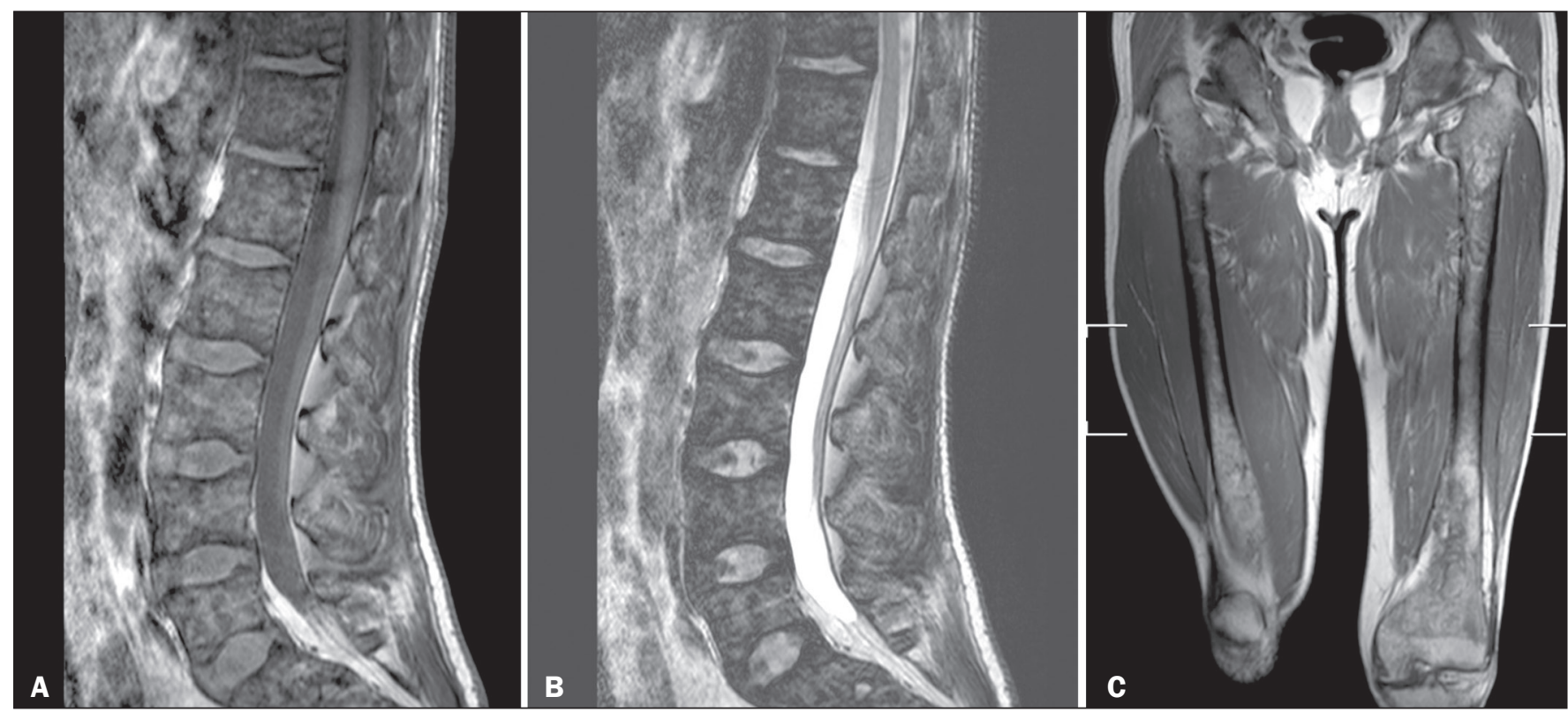

Figure 2. MRI of a 40-year-old man with GD who, despite having extensive bone involvement, did not show poor quality of life, as measured with the SF-36. Sagittal T1 weighted (A) and T2-weighted (B) images of the lumbar spine, showing lower signal intensity in bone marrow than in the disc and presacral fat. The signal intensity score was 5, and the extent score was 1 because the fat surrounding the basivertebral veins was not suppressed, resulting in an L-BMB score of 6. C: Coronal T1-weighted image of both femurs, which were scored 5 for signal intensity and 3 for the extent of involvement, infiltration of epiphyses being detected, resulting in an F-BMB score of 8 . 


\section{DISCUSSION}

GD is an autosomal recessive disease, affecting both genders equally. Some studies have shown a slight predominance in females ${ }^{(2)}$, similar to that observed in our study, in which $55.4 \%$ of the patients were women. In addition, the mean age of our patients was 38.2 years (range, $17-70$ years), similar to the 34.7 years (range, $1-90$ years) reported in the "The Gaucher Registry", a multicenter study conducted in $2000^{(25)}$.

Bone involvement in type 1 GD usually has a progressive course, leading to disability and dramatic deterioration that may be related to osteoporosis, avascular necrosis, femoral fractures, or spinal fractures ${ }^{(26,27)}$. Most affected patients have bone lesions at diagnosis, and such skeletal involvement, which is often not properly recognized, may be the most debilitating aspect of $\mathrm{GD}^{(27)}$. To analyze the involvement of bone marrow and the response to therapy in GD, the BMB score ${ }^{(3,24)}$ has been shown to correlate well with other measures of bone marrow infiltration, such as Dixon quantitative chemical shift imaging, the BMB score having the advantage of being more widely available because it can be determined from standard MRI sequences without the need for proprietary software and special sequences $^{(1,27-29)}$.

In the present study, we detected bone complications in 9 of the 18 patients evaluated, the main ones being femoral infarction and avascular necrosis of the femoral head. The evaluation and monitoring of bone involvement is an important element in the clinical management of GD, allowing treatment to be optimized before the complications become irreversible ${ }^{(11)}$. The risk of infarction and avascular necrosis has been shown to be lower in patients who begin ERT within two years after diagnosis than in those who experience delays of more than two years between diagnosis and treatment ${ }^{(19,20)}$. That implies that early diagnosis has prognostic value in GD.

In type $1 \mathrm{GD}$, bone involvement may not reflect the involvement of other organs; severe skeletal disease may occur in patients with mild or no visceral and hematological involvement ${ }^{(18-20)}$. Nevertheless, our study demonstrated a good correlation between the BMB scores and splenic volume, the total BMB score showing a stronger correlation than that observed for the segmented (L-BMB and F-BMB) scores. That suggests that there is a relationship between the presence of aggressive bone disease (characterized by high BMB scores) and visceral involvement (characterized by increased splenic volume) in GD. However, we found no significant correlation between the BMB score and the SF-36 score. That is probably due to the insidious and silent nature of type 1 GD, which causes indolent and progressive bone changes, with a tendency to affect patient quality of life only later, especially when irreversible bone damage has already occurred. Therefore, early diagnosis of type $1 \mathrm{GD}$, which often occurs in the asymptomatic phase of the disease, and quantification of the extent of bone disease, increase the likelihood of appropriate treatment and prevention of long-term complications, with the subsequent benefit of improving the quality of life of the patients.

In conclusion, our study demonstrated a linear relationship between the BMB score and splenic volume, corresponding to more extensive bone disease in individuals with massive splenomegaly. No correlation was found between the extent of bone disease and quality of life, illustrating the insidious and silent progression of GD. Therefore, we emphasize the importance of early diagnosis and monitoring of bone changes in patients with GD, even in those who are asymptomatic, in order to provide appropriate treatment and prevent bone complications, thus improving the prognosis and quality of life of these patients.

\section{REFERENCES}

1. Maas M, Poll LW, Terk MR. Imaging and quantifying skeletal involvement in Gaucher disease. Br J Radiol. 2002;75 Suppl 1:A13-24.

2. Martins AM, Lobo CL, Sobreira EAP, et al. Tratamento da doença de Gaucher: um consenso brasileiro. Rev Bras Hematol Hemoter. 2003;25:89-95.

3. Maas M, van Kuijk C, Stoker J, et al. Quantification of bone involvement in Gaucher disease: MR imaging bone marrow burden score as an alternative to Dixon quantitative chemical shift MR imaging-initial experience. Radiology. 2003;229:554-61.

4. Maas M, Hollak CEM, Akkerman EM, et al. Radiology of Gaucher disease (type 1) and bone manifestations: the Dutch experience. J Belg Soc Radiol. 2006;89:318-21.

5. Kamath RS, Lukina E, Watman N, et al. Skeletal improvement in patients with Gaucher disease type 1: a phase 2 trial of oral eliglustat. Skeletal Radiol. 2014;43:1353-60.

6. Mariani G, Erba PA. Bone metabolism: implications for Gaucher disease. Clin Ther. 2008;30 Suppl 3:S81-3.

7. Beutler E, Demina A, Laubscher K, et al. The clinical course of treated and untreated Gaucher disease. A study of 45 patients. Blood Cells Mol Dis. 1995;21:86-108.

8. Maas M, Hangartner T, Mariani G, et al. Recommendations for the assessment and monitoring of skeletal manifestations in children with Gaucher disease. Skeletal Radiol. 2008;37:185-8.

9. Morales LE. Gaucher's disease: a review. Ann Pharmacother. 1996; 30:381-8.

10. Poll LW, Maas M, Terk MR, et al. Response of Gaucher bone disease to enzyme replacement therapy. Br J Radiol. 2002;75 Suppl 1:A25-36.

11. Deegan PB, Pavlova E, Tindall J, et al. Osseous manifestations of adult Gaucher disease in the era of enzyme replacement therapy. Medicine (Baltimore). 2011;90:52-60.

12. vom Dahl S, Poll L, Di Rocco M, et al. Evidence-based recommendations for monitoring bone disease and the response to enzyme replacement therapy in Gaucher patients. Curr Med Res Opin. 2006; 22:1045-64.

13. Robertson PL, Maas M, Goldblatt J. Semiquantitative assessment of skeletal response to enzyme replacement therapy for Gaucher's disease using the bone marrow burden score. AJR Am J Roentgenol. 2007; 188:1521-8.

14. Maas M, Hollak CEM, Akkerman EM, et al. Quantification of skeletal involvement in adults with type I Gaucher's disease: fat fraction measured by Dixon quantitative chemical shift imaging as a valid parameter. AJR Am J Roentgenol. 2002;179:961-5.

15. Poll LW, vom Dahl S, Koch JA, et al. Gaucher disease: MR evaluation of bone marrow features during treatment with enzyme replacement. Rofo. 2001;173:931-7. 
16. Laudemann K, Moos L, Mengel K, et al. Evaluation of bone marrow infiltration in non-neuropathic Gaucher disease patients with use of whole-body MRI - a retrospective data analysis. Rofo. 2015 ; 187:1093-8.

17. DeMayo RF, Haims AH, McRae MC, et al. Correlation of MRIbased bone marrow burden score with genotype and spleen status in Gaucher's disease. AJR Am J Roentgenol. 2008;191:115-23.

18. Poll LW, Cox ML, Godehardt E, et al. Whole body MRI in type I Gaucher patients: evaluation of skeletal involvement. Blood Cells Mol Dis. 201 1;46:53-9.

19. Mistry PK, Weinreb NJ, Kaplan P, et al. Osteopenia in Gaucher disease develops early in life: response to imiglucerase enzyme therapy in children, adolescents and adults. Blood Cells Mol Dis. $2011 ; 46: 66-72$.

20. Fedida B, Touraine S, Stirnemann J, et al. Bone marrow involvement in Gaucher disease at MRI: what long-term evolution can we expect under enzyme replacement therapy? Eur Radiol. 2015;25:2969-75.

21. Ferreira JS, Ferreira VLPC, Ferreira DC. Study of Gaucher disease in Santa Catarina. Rev Bras Hematol Hemoter. 2008;30:5-1 1.

22. Lebel E, Dweck A, Foldes AJ, et al. Bone density changes with enzyme therapy for Gaucher disease. J Bone Miner Metab. 2004; 22:597-601.

23. Zhang JP, Pozuelo L, Brennan DM, et al. Association of SF-36 with coronary artery disease risk factors and mortality: a PreCIS study. Prev Cardiol. 2010;13:122-9.

24. Mello RAF, Mello MBN, Pessanha LB. Magnetic resonance imaging and $\mathrm{BMB}$ score in the evaluation of bone involvement in Gaucher's disease patients. Radiol Bras. 2015;48:216-9.

25. Charrow J, Andersson HC, Kaplan P, et al. The Gaucher registry: demographics and disease characteristics of 1698 patients with Gaucher disease. Arch Intern Med. 2000;160:2835-43.

26. Beutler E, Dale GL. Gaucher disease: a century of delineation and research. Enzyme replacement therapy: model and clinical studies. Prog Clin Biol Res. 1982;95:703-16.

27. McCabe ERB, Fine BA, Golbus MS, et al. Gaucher disease. Current issues in diagnosis and treatment. JAMA. 1996;275:548-53.

28. Beutler E. Newer aspects of some interesting lipid storage diseases: Tay-Sachs and Gaucher's diseases. West J Med. 1977;126:46-54.

29. Rosenthal DI, Mayo-Smith W, Goodsitt MM, et al. Bone and bone marrow changes in Gaucher disease: evaluation with quantitative CT. Radiology. 1989;170(1 Pt 1):143-6. 